

http://www.diva-portal.org

This is the published version of a paper published in Nordic Pulp \& Paper Research Journal.

Citation for the original published paper (version of record):

Naderi, A., Lindström, T., Erlandsson, J., Sundström, J., Flodberg, G. (2016)

A comparative study of the properties of three nano-fibrillated cellulose systems that have been produced at about the same energy consumption levels in the mechanical delamination step

Nordic Pulp \& Paper Research Journal, 31(3): 364-371

https://doi.org/10.3183/npprj-2016-31-03-p364-371

Access to the published version may require subscription.

N.B. When citing this work, cite the original published paper.

Permanent link to this version:

http://urn.kb.se/resolve?urn=urn:nbn:se:ri:diva-12616 


\title{
A comparative study of the properties of three nano- fibrillated cellulose systems that have been produced at about the same energy consumption levels in the mechanical delamination step
}

\author{
Ali Naderi, Tom Lindström, Johan Erlandsson, Jonas Sundström, and Göran Flodberg
}

\begin{abstract}
KEYWORDS: Nanofibrillated cellulose (NFC); Rheology; Tensile strength properties; Barrier properties.

SUMMARY: The viscosity, tensile strength- and barrier properties of enzymatically pre-treated- $\left(\mathrm{NFC}_{\mathrm{Enz}}\right)$, carboxymethylated- $\left(\mathrm{NFC}_{\mathrm{Carb}}\right)$ and carboxymethyl cellulose (CMC) modified $\left(\mathrm{NFC}_{\mathrm{CMC}}\right)$ nanofibrillated cellulose systems (NFC) that have been produced at about the same energy consumption levels in the mechanical delamination step in the manufacturing of the different NFCs are reported. It was found that $\mathrm{NFC}_{\mathrm{Enz}}$ and $\mathrm{NFC}_{\mathrm{CMC}}$ are characterized by low degrees of fibrillation. Carboxymethylated NFC displayed superior tensile strength properties, lower fiber fragment content and a higher viscosity when compared to $\mathrm{NFC}_{\mathrm{Enz}}$ and $\mathrm{NFC}_{\mathrm{CMC}}$. Interestingly, $\mathrm{NFC}_{\mathrm{Enz}}$ displayed equal or better barrier properties compared to the highly fibrillated $\mathrm{NFC}_{\mathrm{Carb}}$.
\end{abstract}

\section{ADDRESSES OF THE AUTHORS:}

Ali Naderi (ali.naderi@innventia.com)

Tom Lindström (tom.lindstrom@innventia.com)

Jonas Sundström (Jonas.dundstrom@innventia.com) Göran Flodberg (goran.flodberg@innventia.com) Innventia AB, Box 5604 SE-114 86 Stockholm, Sweden. Johan Erlandsson (jerland@kth.se)

Department of Fibre and Polymer Technology, KTH Royal Institute of Technology, Teknikringen 56, SE-100 44 Stockholm, Sweden

Corresponding author: Ali Naderi

Nanofibrillated cellulose (NFC), also known as microfibrillated cellulose (MFC) and cellulose nanofibrils $(\mathrm{CNF})$, is a material that possesses several attractive properties (Klemm et al. 2011; Moon et al. 2011; Dufresne 2013; Lindström et al. 2014). Today, the potential uses of NFC in a variety of applications such as nanocomposites (Berglund 2005), barrier in foodpackaging (Lavoine et al. 2012), conducting materials (Hu et al. 2013), strengthening of paper and cardboard (Wernersson Brodin et al. 2014), and rheological modifiers (Koskinen et al. 2012) are well-recognized. However, the large-scale application of the material is hinged on (among other things) the ability to produce the material at affordable costs by the employment of industrially relevant- and environmentally friendly processes.

Plenty of inventions have, since the pioneering work of the researchers of ITT Rayonier (Herrick 1983; Turbak et al. 1983), made the claim of producing NFC through attractive routes. However, currently there are only a handful of processes that have been identified by the industry as interesting. These processes, which are based on the chemical modification of the cellulosic material prior to its mechanical delamination to produce NFC, are TEMPO-oxidation (Isogai et al. 2011), carboxymethylation (Wågberg et al. 2008), modification of cellulosic fibers by carboxymethyl cellulose (CMC) (Laine et al. 2000; Lindström et al. 2001; Laine et al. 2002) and enzymatic hydrolysis (Henriksson et al. 2007). TEMPO-oxidation allows for the production NFC with a narrow size distribution at low energy consumption levels in the mechanical delamination process. However, the total cost of NFC production is high, since the TEMPOradical has to be recovered (Miyawaki et al. 2010; Tanikoshi et al. 2011; Nuopponen et al. 2015), which makes the NFC material unsuitable for many applications. Therefore, NFC systems that are produced by carboxymethylation, enzymatic hydrolysis or CMCmodification of cellulosic materials are seemingly today processes that have good potential in large-scale applications. In this context, it is interesting to note that the production of carboxymethylated NFC is probably the easiest process to scale up, as the pre-treatment process is today employed in the CMC manufacturing process.

The production and properties of carboxymethylatedand CMC-modified NFCs have been the subject of several reports; see e.g. (Naderi et al. 2015a; Naderi et al. 2015c). It is noted that the properties of enzymatically pre-treated NFC have also been the subject of several studies, see e.g. (Pääkkö et al. 2007; Fall et al. 2014; Nechyporchuk et al. 2015). Nevertheless, it is not possible to make a direct comparison among the systems, which is required for the identification of the proper NFC system for a particular application. This is due to the employment of different sources of cellulosic materials in the NFC manufacturing process, differing extents of the exerted mechanical delamination on the systems, and different delamination methodologies.

Hence, in this communication we set out to compare the properties of enzymatically pre-treated nanofibrillated cellulose $\left(\mathrm{NFC}_{\mathrm{Enz}}\right)$ with those of carboxymethylated $\left(\mathrm{NFC}_{\mathrm{Carb}}\right)$ and $\mathrm{CMC}$-modified $\left(\mathrm{NFC}_{\mathrm{CMC}}\right)$ nanofibrillated cellulose systems, by using the same pulp material, the same delamination technique and at the same energy consumption levels in the delamination process. The properties that were in focus of this study are the (apparent) degree of fibrillation, rheological properties of NFC suspensions, tensile strength of NFC films, and the barrier properties of the same. These properties are of importance for several of the earlier mentioned potential industrial applications for nanofibrillated cellulose. 


\section{Materials and methods}

\section{Material}

A commercial never-dried TCF-bleached sulfite dissolving pulp (trade name: Dissolving Plus) from a mixture of Norway spruce $(60 \%)$ and Scottish pine $(40 \%)$ was obtained from Domsjö Fabriker (Domsjö Mill, Sweden). The pulp has a hemicellulose content of $4.5 \%$ $(\mathrm{w} / \mathrm{w})$ (measured as solubility in $18 \% \mathrm{NaOH}, \mathrm{R} 18$ ) and a lignin content of $0.6 \%(\mathrm{w} / \mathrm{w})$. This pulp was used for the production of different NFC systems.

Polyethyleneimine (PEI) with a molecular weight of about $60 \mathrm{~kg} / \mathrm{mol}$ was purchased from Sigma Aldrich. Silicon wafers were purchased from MMC Electronic Materials Inc. (Italy).

The following materials were used in the enzymatic pretreatment process. $\mathrm{KH}_{2} \mathrm{PO}_{4}$ and $\mathrm{Na}_{2} \mathrm{HPO}_{4}$ (GPR Rectapur) were purchased from VWR (Sweden). These chemicals constitute the phosphate buffer in the enzymatic treatment process (Fig 1). A mono-component endoglucanase enzyme (FiberCare ${ }^{\circledR} R$ ) was obtained from Novozym A/S (Denmark). A microbiocide, 5chloro-2-ethyl-4-isothiazolin-3-one was purchased from Nalco AB (Sweden); the material is used to suppress the bacterial growth in the fiber suspension.

The following materials were employed in the carboxymethylation pre-treatment process. Ethanol (Rectapur) was purchased from VWR (Sweden). Monochloroacetic acid (99\%), acetic acid (ACS reagent), isopropanol (ACS reagent), sodium hydroxide $(\mathrm{NaOH}$, ACS reagent), sodium hydrogen carbonate $\left(\mathrm{NaHCO}_{3}\right)$ and methanol (ACS reagent) were purchased from Sigma Aldrich.

The below-listed materials were used in the pretreatment process of $\mathrm{NFC}_{\mathrm{CMC}}$. Carboxymethyl cellulose (Aquasorb A500), with a degree of substitution of 0.4 and a molecular weight of about $1000 \mathrm{~kg} / \mathrm{mol}$, was obtained from Ashland Inc. (USA). Calcium chloride $\left(\mathrm{CaCl}_{2}, \mathrm{ACS}\right.$ reagent) was purchased from Sigma Aldrich

All chemicals were used as received, and deionized water was used through-out the studies.

\section{Production of NFC systems}

\section{Enzymatically pre-treated nanofibrillated cellulose $\left(\mathrm{NFC}_{\mathrm{Enz}}\right)$}

The manufacturing process is similar to that reported by Naderi et al. (2015b); the route has been schematically presented in Fig 1. In brief, the (never-dried) pulp is refined prior to the enzymatic pre-treatment as a means to increase the accessibility of the cell wall to the enzyme. Thereafter, after the enzymatic pre-treatment, and after a second refining, the pulp was washed and the microbiocide ${ }^{1}$ is added. Finally, the pulp suspension (at varying dry contents) was passed up to five times through a microfluidizer (M-110EH, Microfluidics Corp., USA) at 1700 bar through two Z-shaped chambers with diameters of $200 \mu \mathrm{m}$ and $100 \mu \mathrm{m}$ respectively.

It is noted that conductometric measurements as described by Katz et al. (1984) on the pre-treated pulp (in

\footnotetext{
$110 \mathrm{ml}$ of the biocide was added to $10 \mathrm{~kg}$ of the pulp
} suspension. its sodium counter-ion form) revealed a charge density of about $30 \mu \mathrm{eq} / \mathrm{g}$.

Carboxymethylated nanofibrillated cellulose (NFC $\mathrm{Carb}_{\text {) }}$ The never-dried fibers were first dispersed in water at 10000 revolutions using an ordinary laboratory blender. This was conducted in smaller batches of 30 grams of fibers in two liters of water. The fibers were then solventexchanged to ethanol by washing the fibers in one liter of ethanol four times with a filtering step in between.

The fibers (110 grams) were then impregnated for 30 min with a solution of $10 \mathrm{~g}$ of monochloroacetic acid in $500 \mathrm{ml}$ of isopropanol. Subsequently, the fibers were added in portions to a solution of $16.2 \mathrm{~g}$ of $\mathrm{NaOH}$ in $500 \mathrm{ml}$ methanol and mixed with two liters of isopropanol that had been heated just below its boiling temperature in a five-liter reaction vessel fitted with a condenser. The carboxymethylation reaction was allowed to continue for one hour.

Following the carboxymethylation step, the fibers were filtered and washed in three steps. First, the fibers were washed with 201 of deionized water. Thereafter, the fibers were washed with two liters of acetic acid $(0.1 \mathrm{M})$ and finally with 101 of water. The fibers were then impregnated with two liters $\mathrm{NaHCO}_{3}$ solution $(4 \%$ w/w solution) for 60 minutes in order to convert the carboxyl groups to their sodium form. Then, the fibers were washed with 151 of water and drained on a Büchner funnel.

The total charge of the pulp (and hence the resulting NFC), in its sodium counter-ion form, was determined by means of conductometric titration to be ca $590 \mu \mathrm{eq} / \mathrm{g}$ (degree of substitution (D.S.) $\approx 0.1$ ).

The pre-treated fibers were microfluidized in their sodium form in the same manner as when $\mathrm{NFC}_{\mathrm{Enz}}$ was produced.

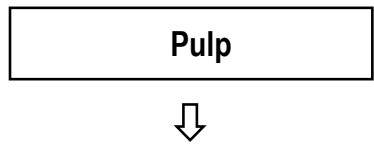

First refining (100 kWh/tonne, $\approx$ oSR 30$)$

\

Enzymatic treatment

$0.17 \mu \mathrm{l} / \mathrm{g}$ fiber

(Phosphate buffer, $\mathrm{pH} \approx 7$ ) Incubation at $50^{\circ} \mathrm{C}$ for $2 \mathrm{~h}$

$\sqrt{3}$

Second refining (400 kWh/tonne, $\approx^{\circ} S R$ 90)

$\Omega$

Microfluidization $(\approx 0.1-3 \%(\mathrm{w} / \mathrm{w}), 1700 \mathrm{bar})$

Fig 1 - Schematic presentation of the different steps that are involved in the manufacturing process of $\mathrm{NFC}_{\mathrm{Enz}}$. 


\section{Carboxymethyl cellulose grafted nanofibrillated cellulose ( $\mathrm{NFC}_{\mathrm{CmC}}$ )}

A detailed description of the manufacturing process of $\mathrm{NFC}_{\mathrm{CMC}}$ is reported in (Naderi et al. 2015c). In brief, a $0.5 \%(\mathrm{w} / \mathrm{w})$ stock solution of CMC was added at a dosage of $80 \mathrm{mg} \mathrm{CMC/g}$ pulp and stirred for one hour, upon which $\mathrm{CaCl}_{2}$ was added. The pulp and $\mathrm{CaCl}_{2}$ concentrations were $2.5 \%(\mathrm{w} / \mathrm{w})$ and $50 \mathrm{mM}$, respectively. The mixture was then heated in an oil bath for two hours at $120^{\circ} \mathrm{C}$, after which the excess chemicals were removed by washing the pulp with water as described earlier. The pulp was then ion-exchanged to its hydrogen counter-ion form (with acetic acid), and washed. Conductometric measurements on the modified pulp (in its sodium counter-ion form) revealed a charge density of about $160 \mu \mathrm{eq} / \mathrm{g}$. The CMC-modified pulp was exchanged to its sodium counter-ion form and was subsequently delaminated in the same manner as $\mathrm{NFC}_{\mathrm{Enz}}$ and $\mathrm{NFC}_{\text {Carb. }}$.

\section{Rheological investigations}

The rheological studies were conducted on samples that after their manufacturing had been stored in a fridge $\left(5^{\circ} \mathrm{C}\right)$ for at least three days, and then equilibrated overnight at room temperature.

The investigations were performed using a Kinexus stress controlled rotational rheometer (Malvern Instruments, UK) together with the software rSpace (Malvern Instruments, UK). A standard (ISO 3219/DIN 53019) metal concentric cylinder (bob and cup) geometry with serrated surfaces was used (to minimize slippage effects (Buscall 2010)) in the studies. The height and distance between the serrations were $300 \mu \mathrm{m}$ and $1000 \mu \mathrm{m}$, respectively. The diameter and length of the bob were 25 and $37.5 \mathrm{~mm}$, respectively; the diameter and wall height of the cup were 27.5 and $62.5 \mathrm{~mm}$, respectively. A working gap of $9.15 \mathrm{~mm}$ was employed in the measurements. The set experimental temperature was $25^{\circ} \mathrm{C}$; the samples were covered with a protective hood during the measurements.

The NFC samples were sheared at $100 \mathrm{~s}^{-1}$ for one minute in the measuring chamber, as a mean to even out the heterogeneities, and then were left to equilibrate for two minutes before conducting the measurements.

The controlled shear rate measurements were conducted in the range of 0.1-1000 s-1. Integration time per measuring point was set to 30 seconds for samples with a consistency of $0.5 \%(\mathrm{w} / \mathrm{w})$ or higher; the time per measuring point was set to $3 \mathrm{~min}$ for lower concentrations.

It is pointed out that the recorded rheological responses are viewed as apparent, as detailed knowledge about the motion of the constituents of the systems and behaviour of the entire suspension is required to draw firmer conclusions.

\section{Preparation of NFC-films}

Samples with dry contents of about $0.1 \%(\mathrm{w} / \mathrm{w})$ were prepared by blending appropriate amounts of the concentrated materials with water, and stirring with a magnetic stirrer, for about $18 \mathrm{~h}$ at $750 \mathrm{rpm}$. The obtained suspensions were thereafter degassed for one hour. Films were prepared first through vacuum filtration of the suspension using $0.65 \mu \mathrm{m}$ DVPP filters (supplied by Millipore), and thereafter drying, in constrained form, in an oven for seven hours at $50^{\circ} \mathrm{C}$.

\section{Tensile strength measurements of films based on NFC}

An MTS tensile strength machine with a Teststar IIS controller (MTS, USA) was used in the investigations. The samples were kept at $50 \% \mathrm{RH} / 23^{\circ} \mathrm{C}$, for at least three days, before conducting the measurements. The samples were weighted after strips were cut out. The length and width of the strips were $45 \mathrm{~mm}$ and $6 \mathrm{~mm}$, respectively; the distance between the grips holding the strips was $30 \mathrm{~mm}$. The strips were then mounted into a tensile strength machine and the mechanical properties were measured at a speed of $100 \% / \mathrm{min}$.

\section{Oxygen permeability measurements}

The oxygen transmission rate (OTR) was monitored with a Mocon Ox-Tran model 2/20 MH System equipped with a coulometric oxygen sensor (Mocon, Minneapolis, USA). The NFC films were mounted in an isolated diffusion cell, where one side of the films is exposed to oxygen $(99.95 \%)$ at atmospheric pressure. The oxygen, which permeates through the sample, is transported to a coulometric sensor, where the amount of oxygen is measured. The OTR was normalized with respect to the average thickness of the films (measured by scanning electron microscopy) to yield an oxygen permeability value, $\mathrm{OP}$. The measurements were conducted at $23^{\circ} \mathrm{C}$ and $50 \% \mathrm{RH}$, and at $23^{\circ} \mathrm{C}$ and $80 \% \mathrm{RH}$, respectively.

\section{Determination of the apparent efficiency of the delamination process}

Nanofibrillated cellulose samples with a consistency of about $0.02 \%(\mathrm{w} / \mathrm{w})$ were prepared by first blending the concentrated NFC systems with water overnight. The diluted systems were then centrifuged at $1000 \mathrm{~g}$ for $15 \mathrm{~min}$, to remove the larger constituents (e.g. residual fiber fragments).

The suspension concentrations before $\left(\mathrm{c}_{\mathrm{bc}}\right)$ and after $\left(c_{a c}\right)$ the centrifugation treatment were used to estimate the fraction of nano-sized cellulosic materials $\left(\mathrm{c}_{\mathrm{NS}} \%\right.$ $(w / w))$ in the dry content of the suspension:

$$
\mathrm{c}_{\mathrm{NS}} \%(\mathrm{w} / \mathrm{w})=\frac{\mathrm{c}_{\mathrm{ac}}}{\mathrm{c}_{\mathrm{bc}}} \times 100
$$

It is noted that $\mathrm{c}_{\mathrm{NS}}$ denotes the fraction of entities which have the ability to resist phase separation during centrifugation. Furthermore, this method of analysis is based on the assumption that the magnitude of $c_{N S}$ increases with the increasing efficiency of the delamination process.

\section{Atomic force microscopy (AFM) studies}

Atomic force microscopy imaging was performed in air, using ScanAsyst on a Multimode 8 (Bruker, Santa Barbera, CA) with a cantilever having a resonance frequency of $70 \mathrm{kHz}$, a spring constant of $0.4 \mathrm{~N} / \mathrm{m}$ and a nominal tip radius of $2 \mathrm{~nm}$ (SCANASYST-AIR, Bruker, Camarillo, CA).

Nanofibrillated cellulose samples for imaging studies were prepared by centrifugation $(1000 \mathrm{~g} / 15 \mathrm{~min})$ of $0.02 \%(\mathrm{w} / \mathrm{w}) \mathrm{NFC}$ suspensions to remove the larger constituents (e.g. fiber fragments) of the system. 

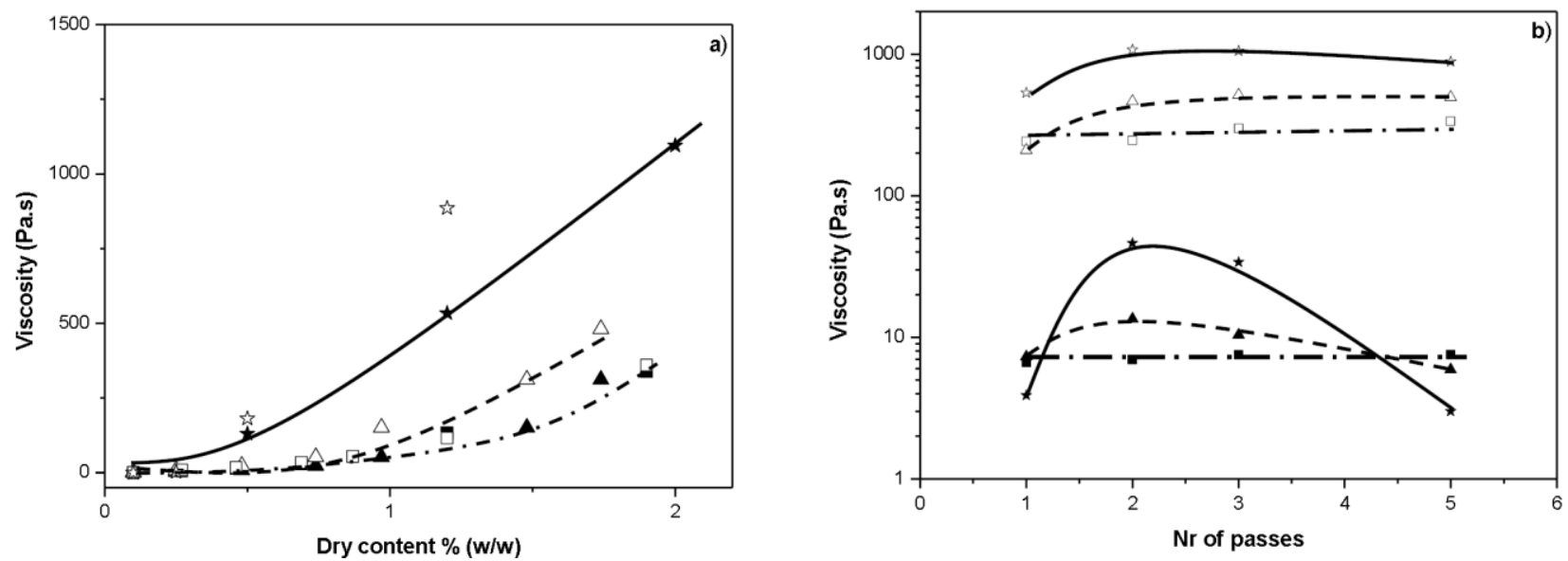

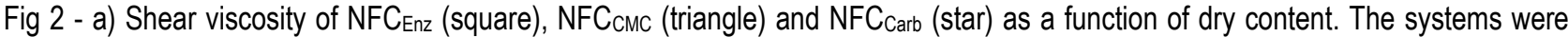
prepared by microfluidization of the pulp: one pass (filled symbols) or five passes (unfilled symbols). b) Shear viscosity of NFCEnz $(0.3 \%$ (w/w): square (filled); $1.9 \%$ (w/w), square (unfilled)), NFC $\mathrm{NMc}(0.3 \%$ (w/w): triangle (filled); $1.7 \%$ (w/w): triangle (unfilled)) and NFC Carb $(0.25 \%$ (w/w): star (filled); $1.2 \%(\mathrm{w} / \mathrm{w})$ : star (unfilled)), as a function of number of passes through the microfluidizer. The reported shear viscosities of the different systems (in (a) and (b)) are measured at $0.1 \mathrm{~s}^{-1}$. The lines are to guide the eye.



Fig 3 - Shear viscosities of NFC Enz (square) and NFC Carb (star)

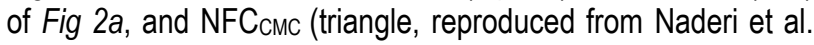
$(2015 \mathrm{c})$ ), that have been diluted to and measured at $0.1 \%$ $(\mathrm{w} / \mathrm{w})$. The viscosities were measured at $0.1 \mathrm{~s}^{-1}$. The lines are to guide the eye

The imaging samples were prepared by first oxidizing fresh silicon wafers $(\approx 1 \times 1 \mathrm{~cm})$ for two minutes at $30 \mathrm{~W}$ power in a plasma oven. The oxidized wafers were subsequently washed with $0.1 \mathrm{M} \mathrm{NaOH}$ and Milli-Q water before being immersed in PEI-solution (0.01 $\mathrm{g} / \mathrm{dm}^{3}$ ) for one second. After rinsing, the wafers were immersed $^{2}$ in different NFC suspensions. After each immersion the wafers were rinsed with Milli-Q water and dried in a flow of filtered $\mathrm{N}_{2}$ gas.

\section{Results and discussion}

The shear viscosity of $\mathrm{NFC}_{\mathrm{Enz}}$ as a function of the dry content and number of passes through the microfluidizer has been summarized in Fig 2a. Attention is drawn to the small differences in the magnitude of the viscosity of $\mathrm{NFC}_{\mathrm{Enz}}$ systems as a function of number of passes (one or five) through the microfluidizer. This can be rationalized

2 The immersion times were three minutes for $\mathrm{NFC}_{E n z}$ and $\mathrm{NFC}_{\mathrm{CMC}}$, and ten seconds for $\mathrm{NFC}_{\text {carb. }}$. (as will be discussed below) by the low susceptibility of enzymatically pre-treated pulp to mechanical shearing. It is noted that similar observations have also been made for nanofibrillated cellulose that has been prepared by mechanical shearing of unmodified pulp (Herrick 1983; Nair et al. 2014). On the other hand, $\mathrm{NFC}_{\mathrm{CMC}}$ displays a greater relative increase in the magnitude of the shear viscosity as compared to $\mathrm{NFC}_{\mathrm{Enz}}$ when the amount of shearing is increased. The relative increase in the magnitude of the shear viscosity (as a function of the number of microfluidization passes) of $\mathrm{NFC}_{\text {Carb }}$ is comparable to that of $\mathrm{NFC}_{\mathrm{CMC}}$. This observation is somewhat surprising, as increasing the charge density of the fibrous system should ease the delamination process (Lindström 1992). A possible explanation for the observation is found in Fig 2b, which shows that the viscosities of $0.25 \%(\mathrm{w} / \mathrm{w})$ and $1.2 \%(\mathrm{w} / \mathrm{w}) \mathrm{NFC}_{\text {Carb }}$ decrease when the number of microfluidization passes exceeds two. It is noted that the viscosity of $\mathrm{NFC}_{\mathrm{CMC}}$ (investigated in the same range as $\mathrm{NFC}_{\text {Carb }}$ ) also decreases, but to a lower extent, while the viscosity of $\mathrm{NFC}_{\mathrm{Enz}}$ remains unchanged.

In Fig 3, the viscosities of the $\mathrm{NFC}_{\mathrm{Enz}}$ systems (in Fig $2 a$ ) that have been produced at different consistencies by one-time microfluidization and subsequently diluted to $0.1 \%(\mathrm{w} / \mathrm{w})$ have been displayed. The results indicate that optimum delamination is obtained by the micro-fluidization at very low pulp concentrations $(\leq 0.1 \%(w / w))$. In comparison, optimum delamination of a CMCmodified pulp (measured at one pass) occurs at about $0.5 \%(\mathrm{w} / \mathrm{w})$ pulp consistency. The optimum delamination of a carboxymethylated pulp (D.S. $\approx 0.1$, one pass) has been reported by the authors (Naderi et al. 2014b) to occur at $\leq 2 \%(\mathrm{w} / \mathrm{w})$. In this connection, it is noted that in the mentioned contribution high shear microfluidization was used to achieve dilution. The optimum pulp concentration decreases, however, to about $1 \%(\mathrm{w} / \mathrm{w})$ when the dilution protocol of this report is employed (Fig 3).

In Fig $4 a-b$, the results of AFM imaging studies conducted on $\mathrm{NFC}_{\mathrm{Enz}}$ systems that have been produced at $0.3 \%(\mathrm{w} / \mathrm{w})$ and $1.9 \%(\mathrm{w} / \mathrm{w})$ have been displayed. A very 
low surface coverage is observed for both systems. The lengths of the entities are in the order of one $\mu \mathrm{m}$; which are similar to the length values that can be discerned from the imaging studies of Pääkkö et al. (2007), who investigated an enzymatically pre-treated NFC that was produced by eight microfluidization passes. On the other hand, the nanofibrils of $\mathrm{NFC}_{\mathrm{Carb}}$ (produced at $2.0 \%$ (w/w), Fig 4c) are comparatively longer and seemingly thinner than those of $\mathrm{NFC}_{\mathrm{Enz}}$. Furthermore, $\mathrm{NFC}_{\mathrm{Carb}}$ is characterized by an entangled state (Naderi et al. 2014a), which can be related to the higher anisotropy of the nanofibrils. The AFM-imaging of $\mathrm{NFC}_{\mathrm{CMC}}$ entities shows expectedly lower amount of adsorbed entities than $\mathrm{NFC}_{\mathrm{Carb}}$. The apparent adsorbed amount of $\mathrm{NFC}_{\mathrm{CMC}}$ is also lower than the $\mathrm{NFC}_{\mathrm{Enz}}$ systems, which possess significantly lower charge densities than $\mathrm{NFC}_{\mathrm{CMC}}$. Furthermore, the fibrillated entities (Fig 4d) are larger and seemingly stiffer than those of $\mathrm{NFC}_{\mathrm{Enz}}$ and $\mathrm{NFC}_{\mathrm{Carb}}$.

The fraction of nanosized materials $\left(\mathrm{c}_{\mathrm{NS}}\right)$ of the different NFC systems together with the estimated energy consumption in the delamination process (EC, Eq 2) of the systems have been summarized in Table 1. The equation employs an energy consumption value of $2221 \mathrm{kWh} /$ tonne for one-time microfluidization at 1600 bar of a $2 \%(w / w)$ fibrous system (Ankerfors 2012). In the relation, $\mathrm{p}, \mathrm{n}$ and $\mathrm{c}$ stand for the applied pressure, the number of passes through the microfluidizer and the concentration of the pulp respectively.

$\mathrm{EC}_{\mathrm{p}, \mathrm{n}, \mathrm{c}}(\mathrm{kWh} /$ tonne $)=\frac{2221 * 2 * \mathrm{p} * \mathrm{n}}{1600 * \mathrm{c}}$

The results in Table 1 indicate that the pulp concentration in the homogenization step is of little importance for the apparent degree of fibrillation $\left(\mathrm{c}_{\mathrm{NS}}\right)$ of $\mathrm{NFC}_{\mathrm{Enz}}$; this observation is in agreement with the observations in Figs $4 a$ and $b$. In addition, the amount of shearing (EC) seems to be of little importance for the degree of fibrillation of $\mathrm{NFC}_{\mathrm{Enz}}$; this observation finds support in the
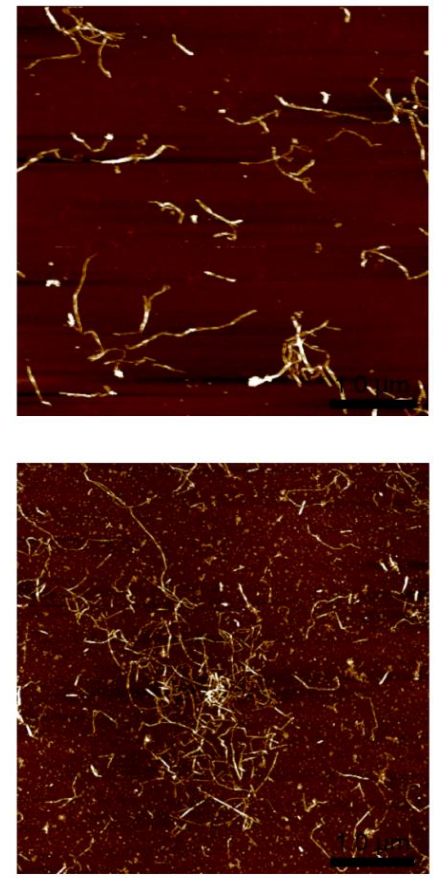

a)

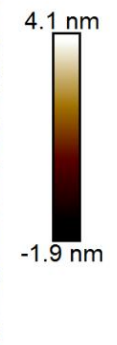

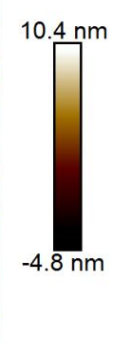

c) rheological studies that were presented in Fig 2, which showed a slight change in the viscosity of the systems as a function of number of microfluidization passes.

$\mathrm{A}_{\mathrm{NS}}$-value of about $30 \%(\mathrm{w} / \mathrm{w})$ is observed for $\mathrm{NFC}_{\mathrm{Carb}}$ (Table 1), which together with the AFM-imaging of the system (Fig 4c) point to a well-delaminated system. On the other hand, a $\mathrm{c}_{\mathrm{NS}}$-value of $10 \%(\mathrm{w} / \mathrm{w})$ is obtained for a $1.7 \%(\mathrm{w} / \mathrm{w}) \mathrm{NFC}_{\mathrm{CMC}}($ Table 1$)$ that is produced by onetime microfluidization. The low $\mathrm{c}_{\mathrm{NS}}$-value of the $\mathrm{NFC}$ together with the small number of entities that are detected by AFM-imaging of the system (Fig 4d) point to a poorly delaminated system. However, contrary to the observations made for $\mathrm{NFC}_{\mathrm{Enz}}$, the $\mathrm{c}_{\mathrm{NS}}$ of the $\mathrm{NFC}_{\mathrm{CMC}}$ system increases significantly $(27 \%(\mathrm{w} / \mathrm{w}))$ when the number of passes through the microfluidizer is increased to five; this points to a substantial improvement of the degree of delamination of the system. Table 2 contains the tensile strength properties of the systems of Table 1. The results show that the strength properties of $\mathrm{NFC}_{\mathrm{Enz}}$ films are only little affected by the number of microfluidization passes (magnitude of EC).

Table 1 - Estimated energy consumption in the delamination process ( $E C, E q 2)$, and the apparent fraction of nano-sized material $\left(\mathrm{CNS}_{\mathrm{NS}}\right)$ for $\mathrm{NFC}_{\mathrm{Enz}}, \mathrm{NFC} \mathrm{C}_{\mathrm{CMC}}$ and $\mathrm{NFC}_{\text {Carb }}$ that have been produced by different numbers of microfluidization passes ("pass").

\begin{tabular}{|c|c|c|}
\hline & $\begin{array}{c}\text { EC } \\
\text { (kWh/tonne) }\end{array}$ & $\mathrm{C}_{\mathrm{NS}}(\%)$ \\
\hline $0.3 \%(w / w) ~ N F C C_{E n z}, 1$ pass & 15732 & 7 \\
\hline $0.3 \%(\mathrm{w} / \mathrm{w}) \mathrm{NFC}_{\mathrm{Enz}}, 5$ pass & 78660 & 10 \\
\hline $1.9 \%(w / w) ~ N F C C_{E n z}, 1$ pass & 2484 & 3 \\
\hline $1.9 \%(w / w) ~ N F C_{E n z}, 5$ pass & 12420 & 5 \\
\hline $2.0 \%(w / w) N_{C} C_{C a r b}, 1$ pass & 2360 & 31 \\
\hline $1.7 \%$ (w/w) NFC $\mathrm{NMC}_{\mathrm{CM}}, 1$ pass & 2776 & 10 \\
\hline $1.7 \%$ (w/w) NFC ${ }_{C M C}, 5$ pass & 13880 & 27 \\
\hline
\end{tabular}

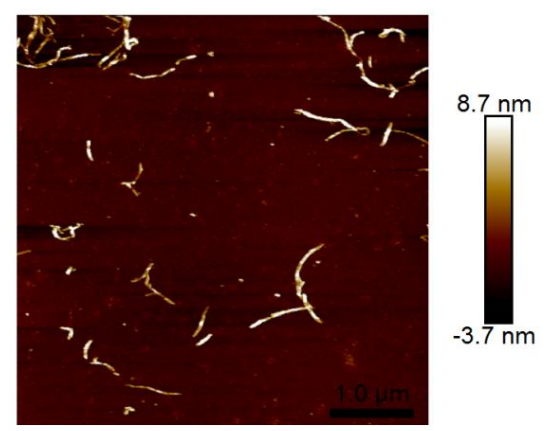

b)

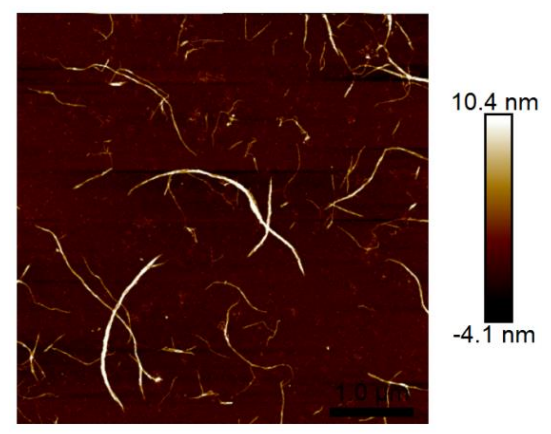

d)

Fig 4 - AFM-imaging studies conducted on NFC systems that have been obtained by one-time microfluidization of different pre-




For example, increasing the number of passes to five (multiplying EC by five) increases tensile strength index (TSI) by about $10 \%$. A similar observation is made if dilute $(0.3 \%(\mathrm{w} / \mathrm{w}))$ pulp suspensions are microfluidized compared to concentrated $(1.9 \%(\mathrm{w} / \mathrm{w}))$ suspensions: approximately six times increase in EC leads to about $10 \%$ increase in TSI. The trend (small change) in the results is in good agreement with the AFM-imaging studies (Fig 4a-b), which showed a little change in the morphology of the NFCs, and a small increase the $\mathrm{c}_{\mathrm{NS}^{-}}$ values of the systems (Table 1). However, a significant difference $\quad(>200 \%)$ in viscosity is observed when the $0.3 \%(\mathrm{w} / \mathrm{w})$ and $1.9 \%(\mathrm{w} / \mathrm{w}) \quad \mathrm{NFC}_{\mathrm{Enz}}$ systems are compared (Fig 3). This can be rationalized by the higher sensitivity of rheological measurements as compared to the other methods of study (Naderi et al. 2015a).

It is of interest to compare the tensile strength properties of $\mathrm{NFC}_{\mathrm{Enz}}$ with the properties of $\mathrm{NFC}_{\mathrm{CMC}}$ and $\mathrm{NFC}_{\mathrm{Carb}}$. The results in Table 2 show that at one-time microfluidization and about the same EC, films based on $\mathrm{NFC}_{\mathrm{CMC}}$ have the lowest strength, while films based on $\mathrm{NFC}_{\mathrm{Carb}}$ display the highest strength properties. However, the mechanical properties of $\mathrm{NFC}_{\mathrm{CMC}}$ improve significantly (TSI $\approx 150 \mathrm{kNm} / \mathrm{kg}$ ) when the amount of shearing (EC) is increased. The observations are in agreement with the findings by rheological- (Fig 2) and centrifugation studies (Table 1).

The OP values of $\mathrm{NFC}_{\mathrm{Enz}}, \mathrm{NFC}_{\mathrm{Carb}}$ and $\mathrm{NFC}_{\mathrm{CMC}}$ that have been prepared by employing the same EC in the mechanical delamination step have been summarized in Table 3. The OP of the $\mathrm{NFC}_{\mathrm{Enz}}$ system is lower than the OP of $\mathrm{NFC}_{\mathrm{Carb}}$, when measured at $23^{\circ} \mathrm{C} / 50 \% \mathrm{RH}$. The OP-values of both systems become however comparable at $23^{\circ} \mathrm{C} / 80 \% \mathrm{RH}$. The barrier property of $\mathrm{NFC}_{\mathrm{CMC}}$ is inferior to both $\mathrm{NFC}_{\mathrm{Enz}}$ and $\mathrm{NFC}_{\mathrm{Carb}}$. The poor barrier property of $\mathrm{NFC}_{\mathrm{CMC}}$ indicates that the system is not efficiently delaminated. In this context, it is recapitulated that the $\mathrm{NFC}_{\mathrm{Enz}}$ manufacturing process involves two refining stages in addition to the microfluidization step, which improve the delamination process. However, no refining is employed in the $\mathrm{NFC}_{\mathrm{CMC}}$ manufacturing process.

Finally, it is noted that the OP values of $\mathrm{NFC}_{\mathrm{Enz}}$ and $\mathrm{NFC}_{\text {Carb }}$ (measured at $23^{\circ} \mathrm{C} / 50 \% \mathrm{RH}$ ) are comparable to those reported for several well-delaminated NFC systems (Siró et al. 2011; Aulin et al. 2012; Chinga-Carrasco, Syverud 2012; Naderi et al. 2016).

\section{Discussions}

Introduction of surface charges into the cell-wall of the fibers is an established route for decreasing the cohesion of the cell wall (Lindström 1992), and the promotion of the delamination process. The $\mathrm{NFC}_{\text {Carb }}$ described in this communication is therefore (due to its high amount of charges and because carboxymethylation leads to the attachment of charges throughout the cell wall) the most efficiently fibrillated NFC among the investigated fibrillated equivalents.

Based on the same reasoning, the charged $(160 \mu \mathrm{eq} / \mathrm{g})$ $\mathrm{NFC}_{\mathrm{CMC}}$ should display a higher degree of fibrillation as compared to low-charged $\mathrm{NFC}_{\mathrm{Enz}}(30 \mu \mathrm{eq} / \mathrm{g})$; however, comparison of the systems paints a complicated picture. At low energy consumption levels, the magnitudes of the $\mathrm{c}_{\mathrm{NS}}$ (Table 1) and rheological properties (Fig 2) of both NFC systems were found to be comparable. The observations might be explained by the notion that in the CMC attachment process, the CMC chains are mainly immobilized in the outer layers of the pulp fibers (Laine et al. 2000). The $\mathrm{NFC}_{\mathrm{Enz}}$ is, on the other hand, more homogeneously fibrillated thanks to the two refining steps in the enzymatic pre-treatment process (Fig 1). At increasing $\mathrm{EC}$ levels the fibrillation of $\mathrm{NFC}_{\mathrm{CMC}}$ was found to significantly improve (Tables 1 and 2, and Fig 2a). However, no significant improvements in the properties of $\mathrm{NFC}_{\mathrm{Enz}}$ were observed when $\mathrm{EC}$ was increased (see e.g. Table 2). Apparently, the presence of a significant amount of charges in the fibrous systems enhances the delamination process. However, the exact mechanisms behind the enhancement of the degree of delamination of $\mathrm{NFC}_{\mathrm{CMC}}$ at higher EC-levels are

Table 2 - Tensile strength properties of sheets based on different NFC systems. EC denotes estimated energy consumption in the microfluidization step (Eq 2); "pass" denotes number of passes through the microfluidizer.

\begin{tabular}{|c|c|c|c|c|c|}
\hline & $\begin{array}{c}\text { EC } \\
\text { (kWh/tonne) }\end{array}$ & $\begin{array}{l}\text { Tensile strength } \\
\text { index }(\mathrm{kNm} / \mathrm{kg})\end{array}$ & $\begin{array}{l}\text { Tensile stiffness } \\
\text { index (MNm/kg) }\end{array}$ & $\begin{array}{c}\text { TEA }{ }^{*} \text { index } \\
(\mathrm{kNm} / \mathrm{kg})\end{array}$ & $\begin{array}{c}\text { Strain } \\
(\%)\end{array}$ \\
\hline $0.3 \%(w / w) \quad N F C_{E n z}, 1$ pass & 15732 & $113 \pm 7$ & $8.7 \pm 0.4$ & $4.3 \pm 1.0$ & $5.1 \pm 1.0$ \\
\hline $0.3 \%(w / w) \quad N F C_{E n z}, 5$ pass & 78660 & $126 \pm 7$ & $8.9 \pm 0.4$ & $3.5 \pm 0.8$ & $3.9 \pm 0.7$ \\
\hline $1.9 \%(w / w) N_{E n z}, 1$ pass & 2484 & $102 \pm 5$ & $8.9 \pm 1.0$ & $2.4 \pm 0.6$ & $3.2 \pm 0.5$ \\
\hline $1.9 \%(w / w) \quad N F C_{E n z}, 5$ pass & 12420 & $107 \pm 6$ & $7.8 \pm 1.3$ & $2.7 \pm 0.7$ & $3.5 \pm 0.7$ \\
\hline $2.0 \%(w / w) N^{N F C} C_{\text {arb }}, 1$ pass & 2359 & $166 \pm 16$ & $9.1 \pm 0.7$ & $7.7 \pm 1.9$ & $6.6 \pm 1.3$ \\
\hline $1.7 \%(\mathrm{w} / \mathrm{w}) \mathrm{NFC}$ смс, 1 pass & 2776 & $91 \pm 7$ & $8.3 \pm 0.8$ & $1.8 \pm 0.6$ & $2.8 \pm 0.7$ \\
\hline $1.7 \%(w / w) N^{N} C_{\text {смс, }} 5$ pass & 13880 & $150 \pm 11$ & $9.7 \pm 0.2$ & $5.2 \pm 1.1$ & $5.1 \pm 1.0$ \\
\hline
\end{tabular}

*Tensile energy absorption.

Table 3 - Oxygen permeability value (OP) of sheets based on different NFC systems. "pass" denotes number of passes through the microfluidizer.

\begin{tabular}{|c|c|c|c|}
\hline & $\begin{array}{c}\text { EC } \\
\text { kWh/tonne }\end{array}$ & $\begin{array}{c}\mathrm{OP}\left(23^{\circ} \mathrm{C} / 50 \% \mathrm{RH}\right) \\
\left(\mathrm{cm}^{3} \mu \mathrm{mm}^{-2} \mathrm{~d}^{-1} \mathrm{kPa}^{-1}\right)\end{array}$ & $\begin{array}{c}\mathrm{OP}\left(23^{\circ} \mathrm{C} / 80 \% \mathrm{RH}\right) \\
\left(\mathrm{cm}^{3} \mu \mathrm{mm}^{-2} \mathrm{~d}^{-1} \mathrm{kPa}^{-1}\right)\end{array}$ \\
\hline $1.9 \%$ (w/w) NFC Enz, $_{1}$ pass $^{*}$ & 2484 & $0.04 \pm 0.008$ & $15.0 \pm 2.1$ \\
\hline $2.0 \%(\mathrm{w} / \mathrm{w}) \mathrm{NFC} \mathrm{C}_{\text {Carb }}, 1$ pass & 2359 & $0.17 \pm 0.03$ & $12.6 \pm 2.2$ \\
\hline $1.7 \%(w / w) N_{\text {cmc }}, 1$ pass & 2776 & $67 \pm 5$ & Out of range \\
\hline
\end{tabular}


currently not understood by the authors; though it has long been recognized (Turbak et al. 1983) that employment of CMC has beneficial effects on the NFC manufacturing process.

The rheological studies (Fig $2 b$ ) revealed that the shear viscosities of $\mathrm{NFC}_{\mathrm{Carb}}$ and $\mathrm{NFC}_{\mathrm{CMC}}$ decrease (at different rates) with increasing number of microfluidization passes, while the viscosity of $\mathrm{NFC}_{\mathrm{Enz}}$ remains constant. The latter can be attributed to the low susceptibility of $\mathrm{NFC}_{\mathrm{Enz}}$ to the delamination process (as discussed above). On the other hand, the lowering in the viscosity of the other NFC systems can be rationalized with the breaking of the nanofibrils at excessive shearing. The carboxymethylated NFC is more easily delaminated than $\mathrm{NFC}_{\mathrm{CMC}}$. Hence, the nanofibrils of $\mathrm{NFC}_{\mathrm{Carb}}$ are broken at comparatively lower applied excessive shearing as compared to the $\mathrm{NFC}_{\mathrm{CMC}}$ system. In this context, it is noted that the detrimental impact of excessive shearing on the NFC properties have also been reported in several other contributions, see e.g. (Iwamoto et al. 2007; Josset et al. 2014; Naderi et al. 2016).

The investigation further revealed that the OP of the lesser delaminated $\mathrm{NFC}_{\mathrm{Enz}}$ is comparable or lower than the highly delaminated $\mathrm{NFC}_{\text {Carb }}$ (Table 3). It could be hypothesized that the superior OP-values of $\mathrm{NFC}_{\mathrm{Enz}}$ are due to the lower charge density, and hence lower hygroscopicity, of the system as compared to the $\mathrm{NFC}_{\mathrm{Carb}}$ (the reasoning has been employed to explain the barrier properties of phosphorylated NFC systems that differed in their charge densities (Naderi et al. 2016)). However, this hypothesis is contradicted by the OP of the mentioned systems measured at $23^{\circ} \mathrm{C} / 80 \% \mathrm{RH}$, which are comparable. A more probable explanation is postulated to be the low mobility of the constituents of the NFC systems at moderate humidity conditions. However, at higher humidity conditions the OP deteriorates more quickly for the system $\left(\mathrm{NFC}_{\mathrm{Enz}}\right)$ that has a broader size distribution (Fig 4a-b, Table 1).

The combined investigations indicate that $\mathrm{NFC}_{\mathrm{Enz}}$ is a competitive alternative in applications (e.g. food packaging) that demand good oxygen barrier properties. On the other hand, carboxymethylated NFC is probably best served in applications, which demand excellent strength properties combined with a low amount of fiber fragments, or in applications where high viscosity effects at comparatively low applied amounts of NFC are required.

\section{Conclusions}

The rheological, tensile strength, barrier and strengthening properties of enzymatically pre-treated-, CMC-modified- and carboxymethylated nanofibrillated cellulose systems, that were produced at about the same energy consumption levels in the mechanical delamination step (and by using the same pulp), were reported for the first time. It was found that $\mathrm{NFC}_{\text {Carb }}$ displayed the highest degree of fibrillation, while $\mathrm{NFC}_{\mathrm{Enz}}$ and $\mathrm{NFC}_{\mathrm{CMC}}$ were characterized by low degrees of fibrillation. The barrier properties of $\mathrm{NFC}_{\mathrm{Enz}}$ were, however, found to be superior to that of $\mathrm{NFC}_{\mathrm{CMC}}$, and better than $\mathrm{NFC}_{\text {Carb }}$ at moderate humidity conditions.

\section{Acknowledgements}

Gunborg Glad-Nordmark, Åsa Engström and Åsa Blademo are thanked for their competent supporting work.

BillerudKorsnäs, Borregaard, Fibria, Hansol Paper, Holmen, ITC, Mercer, Stora Enso and Södra are acknowledged for their financial contribution.

\section{Literature}

Ankerfors, M. (2012): Microfibrillated cellulose: Energy-efficient preparation techniques and key properties, Licentiate thesis, KTH Royal Institute of Technology, Stockholm, Sweden

Aulin, C., Salazar-Alvarez, G. and Lindström, T. (2012): High strength, flexible and transparent nanofibrillated cellulosenanoclayt biohybrid films with tunable oxygen and water vapor permeability, Nanoscale 4(20), 6622-6628.

Berglund, L. A. (2005): Cellulose-based nanocomposites Mohanty, A., Misra, M, and Drzal, L. (eds) (ed.), Natural fibres, biopolymers and biocomposites, Taylor \& Francis, pp. 807-832.

Buscall, R. (2010): Letter to the editor: Wall slip in dispersion rheometry, J. Rheol. 54(6), 1177-1183.

Chinga-Carrasco, G. and Syverud, K. (2012): On the structure and oxygen transmission rate of biodegradable cellulose nanobarriers, Nanoscale Res. Lett. 7(1), 1-6.

Dufresne, A. (2013): Nanocellulose: a new ageless bionanomaterial, Mater. Today 16(6), 220-227.

Fall, A. B., Burman, A. and Wågberg, L. (2014): Cellulosic nanofibrils from eucalyptus, acacia and pine fibers, Nord. Pulp Pap. Res. J. 29(1), 176-184.

Henriksson, M., Henriksson, G., Berglund, L. A. and Lindström, T. (2007): An environmentally friendly method for enzyme-assisted preparation of microfibrillated cellulose (MFC) nanofibers, Eur. Polym. J. 43(8), 3434-3441.

Herrick, F. W. (1983): Redispersible microfibrillated cellulose, vol. US Pat. 4,481,076, ITT Corp.

Hu, L., Zheng, G., Yao, J., Liu, N., Weil, B., Eskilsson, M., Karabulut, E., Ruan, Z., Fan, S., Bloking, J. T., McGehee, M. D., Wågberg, L. and Cui, Y. (2013): Transparent and conductive paper from nanocellulose fibers, Energy Environ. Sci. 6, 513-518.

Isogai, A., Saito, T. and Fukuzumi, H. (2011): TEMPOoxidized cellulose nanofibers, Nanoscale 3(1), 71-85.

Iwamoto, S., Nakagaito, A. N. and Yano, H. (2007): Nanofibrillation of pulp fibers for the processing of transparent nanocomposites, Appl. Phys. A 89(2), 461-466.

Josset, S., Orsolini, P., Siqueira, G., Tejado, A., Tingaut, P. and Zimmermann, T. (2014): Energy consumption of the nanofibrillation of bleached pulp, wheat straw and cecycled newspaper through a grinding process, Nord. Pulp Pap. Res. J. 29(1), 167-175.

Katz, S., Beatson, R. P. and Scallan, A. M. (1984): The determination of strong and weak acidic groups in sulfite pulps, Sven. Papperstidn. 87, R48-R53.

Klemm, D., Kramer, F., Moritz, S., Lindström, T., Ankerfors, M., Gray, D. and Dorris, A. (2011): Nanocelluloses: A new family of nature-based materials, Angew. Chem., Int. Ed. 50(24), 5438-5466.

Koskinen, T., Gustafsson, H. and Teirfolk, J.-E. (2012): A method and an apparatus for adding an additive to a cement- 
like composition, WO2012143617A1, UPM-Kymmene Corporation, Finland.

Laine, J., Lindström, T., Nordmark, G. G. and Risinger, G. (2000): Studies on topochemical modification of cellulosic fibers. Part 1. Chemical conditions for the attachment of carboxymethyl cellulose onto fibers, Nord. Pulp Pap. Res. J. 15(5), 520-526.

Laine, J., Lindström, T., Nordmark, G. G. and Risinger, G. (2002): Studies on topochemical modification of cellulosic fibres. Part 2. The effect of carboxymethyl cellulose attachment on fibre swelling and paper strength, Nord. Pulp Pap. Res. J. 17(1), 50-56.

Lavoine, N., Desloges, I., Dufresne, A. and Bras, J. (2012): Microfibrillated cellulose - Its barrier properties and applications in cellulosic materials: A review, Carbohydr. Polym. 90, 735764

Lindström, T. (1992): Chemical factors affecting the behavior of fibers during papermaking, Nord. Pulp Pap. Res. J. 7(4), 181 192

Lindström, T., Aulin, C., Naderi, A. and Ankerfors, M. (2014): Microfibrillated cellulose, Encyclopedia of polymer science and technology, John Wiley \& Sons, Inc., pp. 1-34.

Lindström, T., Glad-Nordmark, G., Risinger, G. and Laine, J. (2001): Method for modifying cellulose-based fiber material, WO2001021890A1. pp. 15 pp.

Miyawaki, S., Katsukawa, S., Abe, H., lijima, Y. and Isogai, A. (2010): Method for recovery/reuse of $\mathrm{N}$-oxyl compound, WO2010116794A1, Nippon Paper Industries Co., Ltd., Japan.

Moon, R. J., Martini, A., Nairn, J., Simonsen, J. and Youngblood, J. (2011): Cellulose nanomaterials review: structure, properties and nanocomposites, Chem. Soc. Rev. 40(7), 3941-3994.

Naderi, A., Lindström, T. and Pettersson, T. (2014a): The state of carboxymethylated nanofibrils after homogenizationaided dilution from concentrated suspensions: a rheological perspective, Cellulose 21(4), 2357-2368.

Naderi, A., Lindström, T. and Sundström, J. (2014b): Carboxymethylated nanofibrillated cellulose: rheological studies, Cellulose 21(3), 1561-1571.

Naderi, A., Lindström, T. and Sundström, J. (2015a): Repeated homogenization, a route for decreasing the energy consumption in the manufacturing process of carboxymethylated nanofibrillated cellulose?, Cellulose 22(2), 1147 1157.

Naderi, A., Lindström, T., Sundström, J. and Flodberg, G. (2015b): Can redispersible low-charged nanofibrillated cellulose be produced by the addition of carboxymethyl cellulose?, Nord. Pulp Pap. Res. J. 30(4), 568-577.

Naderi, A., Lindström, T., Sundström, J., Pettersson, T., Flodberg, G. and Erlandsson, J. (2015c): Microfluidized carboxymethyl cellulose modified pulp: a nanofibrillated cellulose system with some attractive properties, Cellulose 22(2), 1159-1173.

Naderi, A., Lindström, T., Weise, C. F., Flodberg, G., Sundström, J., Junel, K., Erlandsson, J. and Runebjörk, A (2016): Phosphorylated nanofibrillated cellulose: production and properties, Nord. Pulp Pap. Res. J. 31(1), 22-31.
Nair, S. S., Zhu, J. Y., Deng, Y. and Ragauskas, A. (2014): Characterization of cellulose nanofibrillation by microgrinding, $\mathrm{J}$. Nanopart. Res. 16(4), 2349.

Nechyporchuk, O., Belgacem, M. and Pignon, F. (2015): Concentration effect of TEMPO-oxidized nanofibrillated cellulose aqueous suspensions on the flow instabilities and small-angle $\mathrm{X}$-ray scattering structural characterization, Cellulose, 22(4), 1-14.

Nuopponen, M., Kuutti, L. and Rovio, S. (2015): Method for recovering heterocyclic nitroxyl catalyst, WO2015086901A1, UPM-Kymmene Corporation, Finland .

Pääkkö, M., Ankerfors, M., Kosonen, H., Nykänen, A., Ahola, S., Österberg, M., Ruokolainen, J., Laine, J., Larsson, P. T., Ikkala, O. and Lindström, T. (2007): Enzymatic hydrolysis combined with mechanical shearing and high-pressure homogenization for nanoscale cellulose fibrils and strong gels, Biomacromolecules 8(6), 1934-1941.

Siró, I., Plackett, D., Hedenqvist, M., Ankerfors, M. and Lindström, T. (2011): Highly transparent films from carboxymethylated microfibrillated cellulose: The effect of multiple homogenization steps on key properties, J. Appl. Polym. Sci. 119(5), 2652-2660.

Tanikoshi, H., Kamino, K., Mori, E., Goi, Y., Ikumi, Y., Noda, H. and Isogai, A. (2011): Manufacture of oxidized polysaccharides with good recovery of $\mathrm{N}$-oxyl catalysts, JP2011116865A, Daiichi Kogyo Seiyaku Co., Ltd., Japan.

Turbak, A. F., Snyder, F. W. and Sandberg, K. R. (1983): Suspensions containing microfibrillated cellulose, US4,378,381, ITT Corp.

Wågberg, L., Decher, G., Norgren, M., Lindström, T., Ankerfors, M. and Axnäs, K. (2008): The build-up of polyelectrolyte multilayers of microfibrillated cellulose and cationic polyelectrolytes, Langmuir 24(3), 784-795.

Wernersson Brodin, F., Weiby Gregersen, $\varnothing$. and Syverud, K. (2014): Cellulose nanofibrils: Challenges and possibilities as a paper additive or coating material - A review, Nord. Pulp Pap. Res. J. 29(1), 156-166.

Manuscript received February 16, 2016 Accepted June 15, 2016 